\title{
Accuracy of recall of histories of oral contraceptive use
}

\author{
ROGER GLASS*, BRIDGET JOHNSON, AND MARTIN VESSEY \\ Department of Social and Community Medicine, University of Oxford
}

\begin{abstract}
SUMMARY
Published retrospective studies of the relationship between the use of oral contraceptives and disease have assumed that women are able to recall their oral contraceptive histories with reasonable accuracy. The validity of this assumption has been investigated by comparing oral contraceptive histories obtained from 75 women attending family planning clinics with the information contained in the clinic records. It is concluded that simple measures of oral contraceptive use, such as whether the preparations have ever or never been used, whether they are in current use, and the total duration of use, are likely to be remembered with adequate accuracy.
\end{abstract}

\section{INTRODUCTION}

Many retrospective studies of the relationship between the use of oral contraceptives and disease have been published. Among the conditions investigated in this way are venous thrombosis and embolism (Vessey and Doll, 1968), stroke (Collaborative Group for the Study of Stroke in Young Women, 1973), breast neoplasms (Vessey, Doll, and Sutton, 1972), carcinoma-in-situ of the cervix (Thomas, 1972), and cholelithiasis (Boston Collaborative Drug Surveillance Program, 1973). These studies have all assumed that women are able to recall their oral contraceptive histories with reasonable accuracy. We report here the results of a small investigation which provide some information about the validity of this assumption.

\section{SubJects AND Methods}

Women attending one or other of seven clinics run by the Family Planning Association were interviewed by experienced research assistants and asked to recall the names of oral contraceptives they had used, the times when they had been used, and the reasons for discontinuing their use. The interviews were conducted without prior warning before the women had been seen by the clinic nurse or doctor. To be eligible for the investigation, each woman had to have been attending the clinic regularly for at least three years and the clinic records had to indicate that she had had some exposure to oral contraceptives during that time. After each interview had been completed the research assistant abstracted the appropriate information about oral contraceptive use from the clinic records for comparative purposes. This information is known to be comprehensive and accurate and includes details of all oral contraceptive prescriptions made by clinic doctors.

A total of 75 women were interviewed. Of these, $25 \%$ were aged less than 25 years while $31 \%$ were aged 35 years or more; $44 \%$ were of social classes I or II while $9 \%$ were of social classes IV or V; and $27 \%$ had been regularly attending the clinic for seven years or more while $53 \%$ had been doing so for less than five years.

\section{RESULTS}

As an example of the type of data which were collected Fig. 1 compares the overall pattern of the oral contraceptive histories obtained from the women who had been atttending the clinics for seven years or more with the information obtained from the clinic records. Such data are difficult to analyse, but we have abstracted a number of simple statistics in an attempt to summarize some of their main features.

Of the total of 75 women, all but 15 stated that they were currently using oral contraceptives or had been doing so during the three-month interval preceding the date of the interview, a number identical to that indicated by the clinic records. Recall of the interval since the preparations 


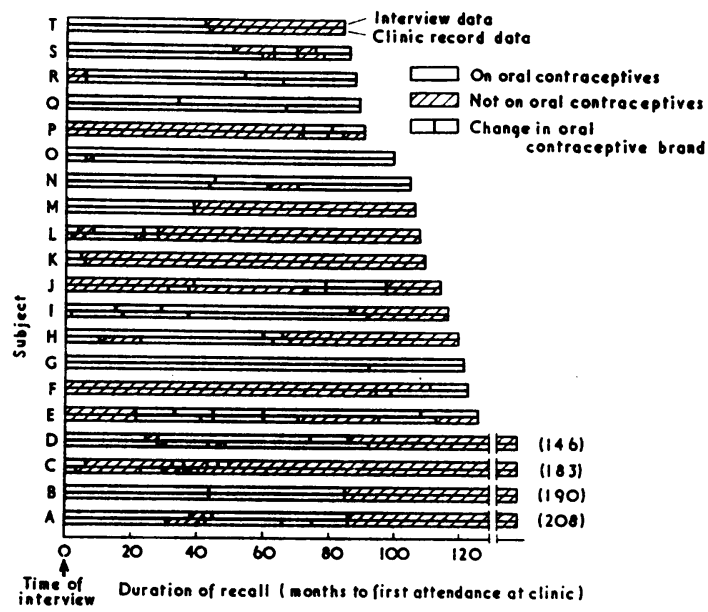

Fic. 1. Comparison of interview data and clinic record data for the 20 women who had been attending the clinics for seven years or more.

were last used by the 15 women who were not current or very recent users of oral contraceptives was remarkably accurate (Fig. 2).

Figure 3 compares the data on total duration of use of oral contraceptives (from the time of the first clinic attendance) obtained from the two sources. Again, the accuracy of recall is high.

A 'break' in oral contraception was defined as an interval lasting three months or more, before

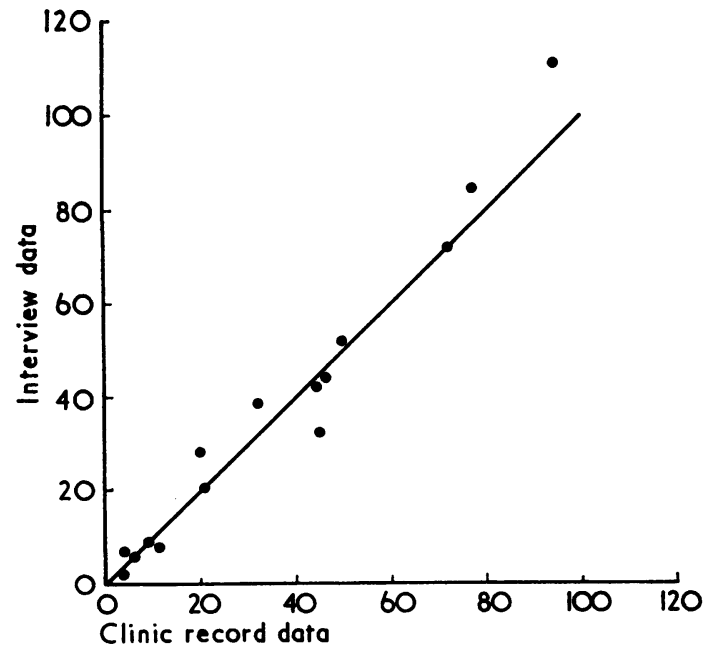

Fic. 2. Interval since oral contraceptives last used (months). Companison of interview data and clinic record data for the 15 women who were not current or very recent users of the preparations.

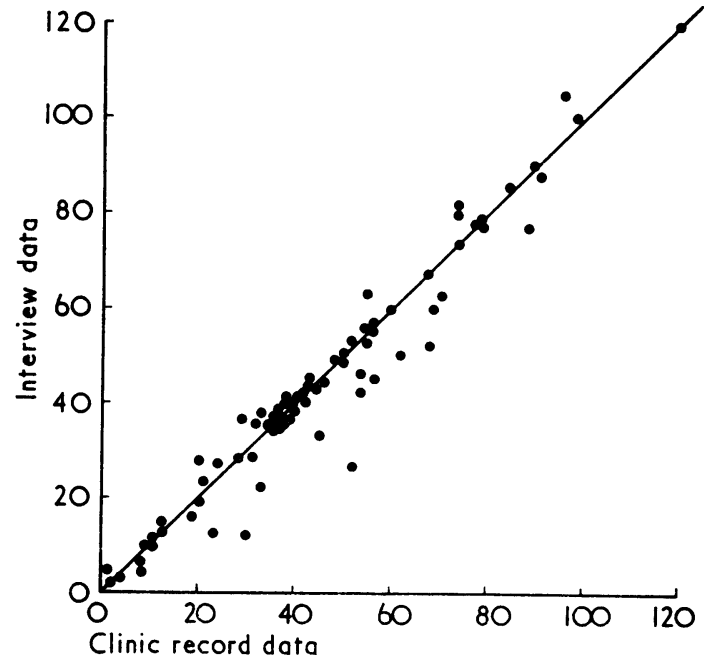

FIG. 3. Total duration of use of oral contraceptives (months). Comparison of interview data and clinic record data for all 75 women.

융 궁

which and after which the preparations were in use. $\frac{}{\mathbb{D}}$ The Table indicates that women frequently failed to recall such breaks. Furthermore, even when they were remembered, they were often inaccurately dated.

TABLE

RECALL OF 'BREAKS' IN ORAL CONTRACEPTIVE USE: THE DATA SHOWN ARE NUMBERS OF WOMEN

\begin{tabular}{c|rrr}
\hline $\begin{array}{c}\text { No. of Breaks- } \\
\text { Clinic Record Data }\end{array}$ & \multicolumn{4}{|c}{$\begin{array}{c}\text { No. of Breaks- } \\
\text { Interview Data }\end{array}$} \\
\cline { 2 - 4 } & 0 & 1 & 2 \\
\hline 0 & 49 & 1 & 0 \\
1 & 0 & 0 & 3 \\
\hline
\end{tabular}

Seventy-nine per cent of the women remembered correctly the name of the preparation they were currently using or had last used, while $74 \%$ remembered correctly the name of the preparation they had first taken while attending the family planning clinic. Recall of the name of the latter preparation was unrelated to the length of time since the preparation had first been prescribed.

Figure 4 compares the data on total duration of use of the four most commonly used oral contraceptives, obtained from the two sources. For the sake of clarity, the information shown is restricted to the 37 women who had been attending the clinics for five or more years at the time of interview. It should be noted that no account has been taken 


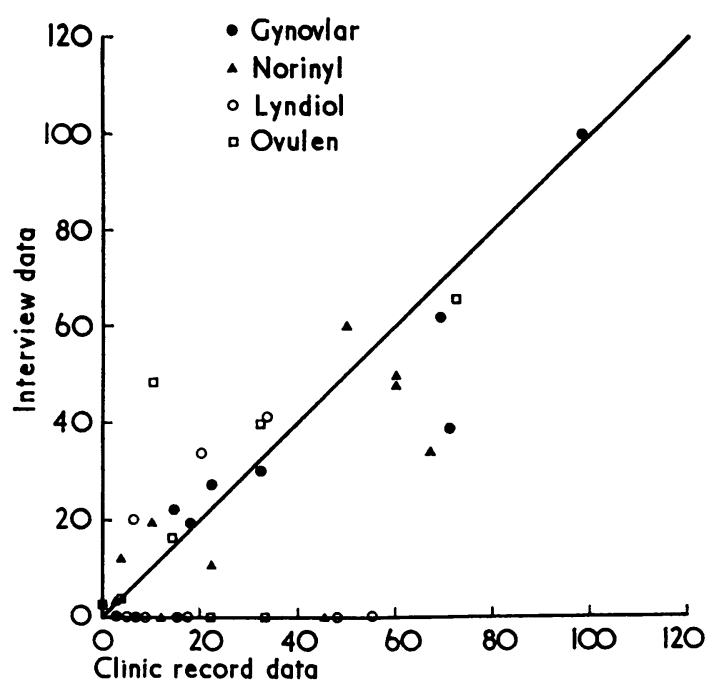

Fig. 4. Total duration of use of particular oral contraceptives (months). Comparison of interview data and clinic recordactata for the 37 women who had been attending the clinics for five years or more.

in this analysis of differences between preparations with the same generic name. Norinyl thus includes both Norinyl-1 and Norinyl-2, Lyndiol includes both Lyndiol and Lyndiol $2 \cdot 5$, and Ovulen includes both Ovulen $1 \mathrm{mg}$ and Ovulen 50 . The cluster of points along the horizontal axis of Fig. 4 represents the substantial number of women who could not remember the names of preparations they had taken (Gynovlar 3 of 10, Norinyl 2 of 10 , Lyndiol 5 of 8, Ovulen 2 of 8). Furthermore, comparison of Figs. 3 and 4 shows that even when the names of preparations were accurately recalled, the duration of their use was less adequately remembered than the total duration of use of all preparations considered together.

\section{Discussion}

The present investigation has a number of important limitations. First, the number of subjects studied is small. Secondly, the women interviewed were of high social class and strongly mocivated towards family planning. To what extent their performance is representative of the general population of women using oral contraceptives is therefore uncertain, but it would be expected that they would be more accurate historians than average. Thirdly, the duration of recall is short, ranging from three to 17 years with a median duration of just under five years. Fourthly, the oral contraceptive history as recorded in the clinic records has been taken as being correct. This seems to be a reasonable assumption but there is no guarantee that note was always made when oral contraceptives were piescribed for a woman but never taken, nor that some women did not occasionally obtain oral contraceptives from a source other than the family planning clinic.

Within the boundaries set by these limitations the present study strongly suggests that women can remember with a considerable degree of accuracy the total duration of their exposure to oral contraceptives and the names of the most recent and the least recent preparations they have taken. Recall of the duration of use of specific preparations and recall of 'breaks' in use appears to be less accurate. Retrospective studies which have been published so far have largely been concerned with simple measures of oral contraceptive use such as whether the preparations have ever or never been used, whether they are in current use, the name of the preparation most recently used, and the total duration of use. The present investigation suggests that such information is likely to be remembered with adequate accuracy.

\section{REFERENCES}

Boston Collaborative Drug Surveillance Program (1973). Oral contraceptives and venous thromboembolic disease, surgically confirmed gall-bladder disease, and breast tumours. Lancet, 1, 1399.

Collaborative Group for the Study of Stroke in YOUNG WOMEN (1973). Oral contraception and increased risk of cerebral ischemia or thrombosis. New Engl. J. Med., 288, 871.

Thомas, D. B. (1972). Relationship of oral contraceptives to cervical carcinogenesis. Obstet. and Gynec., 40, 508.

VESSEY, M. P. and Doll, R. (1968). Investigation of relation between use of oral contraceptives and thromboembolic disease. Brit. med. J., 2, 199.

_, - - and SuTton, P. M. (1972). Oral contraceptives and breast neoplasia: a retrospective study. Brit. med. J., 3, 719. 